\title{
BMJ Open Protocol for study of financial incentives for smoking cessation in pregnancy (FISCP): randomised, multicentre study
}

\author{
Noémi Berlin, ${ }^{1}$ Léontine Goldzahl, ${ }^{2}$ Florence Jusot, ${ }^{2}$ Ivan Berlin ${ }^{3}$
}

To cite: Berlin N, Goldzahl L, Jusot $\mathrm{F}$, et al. Protocol for study of financial incentives for smoking cessation in pregnancy (FISCP): randomised, multicentre study. BMJ Open 2016;6: e011669. doi:10.1136/ bmjopen-2016-011669

- Prepublication history for this paper is available online To view these files please visit the journal online (http://dx.doi.org/10.1136/ bmjopen-2016-011669).

Received 25 February 2016 Revised 5 April 2016 Accepted 25 May 2016

\section{CrossMark}

\footnotetext{
${ }^{1}$ University of Edinburgh, School of Economics, Edinburgh, UK

${ }^{2}$ Leda-Legos, Université Paris-Dauphine, Paris, France ${ }^{3}$ Department of

Pharmacology, Hôpital PitiéSalpêtrière, Faculté de médecine-Université P. \& M. Curie, INSERM U1178, Paris, France
}

Correspondence to Dr Ivan Berlin; ivan.berlin@aphp.fr

\section{ABSTRACT}

Introduction: Maternal smoking during pregnancy is associated with adverse perinatal and postnatal health outcomes. The efficacy of nicotine replacement therapies in helping pregnant smokers to quit is not clearly demonstrated; therefore new interventions should be proposed and assessed. Financial incentives rewarding abstinence from tobacco smoking is one of the promising

options.

Objective: To assess the efficacy of financial incentives on smoking abstinence among French pregnant smokers.

Methods and analysis: Participants: pregnant smokers aged $\geq 18$ years, smoking at least five manufactured or three roll-your-own cigarettes per day, and pregnant for $<18$ weeks of amenorrhoea (WA). Setting: participants will be recruited, included and followed-up at monthly face-to-face visits in 16 maternity wards in France. Interventions: participants will be randomised to a control or an intervention group. After a predefined quit date, participants in the control group will receive $€ 20$ vouchers at the completion of each visit but no financial incentive for smoking abstinence. Participants in the intervention group will be rewarded for their abstinence by vouchers on top of the $€ 20$ show-up fee. The amount of reward for abstinence will increase as a function of duration of abstinence to stimulate longer periods of abstinence. Main outcome measure: complete abstinence from quit date to the last predelivery visit. Secondary outcome measures: point prevalence abstinence, time to relapse to smoking, birth weight, fetal growth restriction, preterm birth. Main data analysis: outcomes will be analysed on an intention-to-treat (ITT) basis. The ITT population is defined as all randomised smoking pregnant women.

Ethics and dissemination: The research protocol was approved by the ethics committee (Comité de Protection des Personnes, CPP) of the Pitié-Salpêtrière Hospital on 15 May 2015, and Amendment No 1 was approved on 13 July 2015 . Results will be presented at scientific meetings and published.

Trial registration number: NCT02606227; Pre-results.

\section{Strengths and limitations of this study}

- Maternal smoking during pregnancy is associated with adverse perinatal and postnatal health outcomes and the most promising intervention seems to be financial incentives to help pregnant smokers quit.

- A randomised open-label study that will be run in 16 maternity wards all over France, with face-to-face monthly visits during pregnancy up to delivery.

- Intervention group: progressively increasing financial incentives (unit of vouchers €20) rewarding abstinence and show-up ( $\mathrm{N}$ to randomise 199). Control group: $€ 20$ vouchers for show-up (N to randomise 199).

- Main outcome measure: continuous and complete abstinence from quit date to delivery

- No long-term (over 6 months) follow-up of infants.

\section{INTRODUCTION}

Smoking is a major public health issue through its contribution to chronic diseases, risk of disability and preventable mortality. Smoking is also one of the most important contributors to socioeconomic inequalities in mortality. People from a low social background are more likely to smoke and find it harder to quit. ${ }^{12}$

The current status of tobacco control in France has largely been criticised by two parliamentary reports ${ }^{3}{ }^{4}$ and by a major report of the Cour des comptes. ${ }^{5}$ Investment in interventions for reducing tobacco prevalence is negligible compared with the social cost of tobacco smoking, estimated to be $€ 120$ billion in $2010 .{ }^{6}$ In addition, interventions are not sufficiently targeted to reach at-risk populations and there is a lack of evaluation of tobacco control interventions in terms of both effectiveness and efficiency.

Among at-risk populations, pregnant women are an important target for tobacco control policies, since maternal smoking during pregnancy (MSDP) is associated with 
perinatal and postnatal adverse health outcomes ${ }^{78}$ such as spontaneous abortion, premature birth and low birth weight. Recent studies have also highlighted its longlasting effects on health outcomes of the offspring. ${ }^{9-15}$ MSDP may increase the risk of psychiatric comorbidity, obesity, asthma and type 2 diabetes. It increases all-cause mortality among offspring. ${ }^{7}$ Cohort studies have reported that smoking in pregnancy is associated with increased risk of childhood retinoblastoma, ${ }^{16}$ brain tumours, ${ }^{17}$ and leukaemia and lymphoma. ${ }^{18} 19$

The last French perinatal survey ${ }^{20}$ reports that, in $2010,30.5 \%$ of pregnant women (total sample 13888 ) were smokers before pregnancy, and $\sim 20 \%$ of the total smoked at least 10 cigarettes per day. In 2010, 17\% of pregnant women smoked in the last trimester, which corresponds to 137180 fetuses exposed in utero to active smoking in the last trimester (802 224 births in $2010^{21}$ ).

To the best of our knowledge, no national data exist on: how many women stop smoking before pregnancy and maintain full abstinence during fertilisation, the first and second trimester, and up to and during delivery; how many smoking women abstain partially during pregnancy and at the time of delivery; and how many relapse, and at what point, after giving birth. Most pregnant smokers reduce their consumption during pregnancy or smoke intermittently, and, if they quit, most of them relapse after delivery, ${ }^{2-25}$ which is a main concern because of postnatal second-hand smoke exposure of the newborn/infant/child. The relapse rate varies according to the country. As for other behavioural data influenced by cultural, socioeconomic and genetic factors, issues concerning smoking during and after pregnancy are not automatically transposable to the population of French pregnant smokers.

Nicotine replacement therapies (NRTs) are considered to be the cornerstone intervention to help smokers quit. Their efficacy has been demonstrated in various populations of smokers. ${ }^{26}$ In pregnant smokers, NRTs are still recommended by French health authorities, ${ }^{27}$ but, because of the lack of conclusive evidence on their efficacy for smoking cessation among pregnant women, recommendations in the UK are more cautious, ${ }^{28}$ and NRTs are not recommended in US guidelines. $^{29}$ Previous trials, ${ }^{30-34}$ two meta-analyses ${ }^{35} 36$ and one sufficiently powered UK study ${ }^{37}$ concluded that NRTs are not effective in helping pregnant smokers stop smoking. A French multicentre, randomised, parallel group, national study found that NRTs, even when adjusted for nicotine uptake by smoking and when administered at higher than usual doses of nicotine, do not result in higher abstinence rates than placebo. ${ }^{38}$ The most recent Cochrane meta-analysis concluded that, when all NRT trials in pregnancy were taken into account, NRT use can be associated with an increased rate of abstinence in late pregnancy; however, when non-placebo-controlled and potentially biased trials were excluded, placebocontrolled randomised trials did not show efficacy of NRT use over placebo. ${ }^{39}$ Furthermore, there is no evidence that NRTs in pregnancy have either benefit or adverse effect on birth outcomes. ${ }^{39}$

Contingency management interventions, such as providing tangible rewards for cigarette abstinence, are an alternative to NRTs.

\section{FINANCIAL INCENTIVES AND TOBACCO CONSUMPTION}

The theoretical framework of the economics of smoking $^{40}{ }^{41}$ provides several mechanisms to explain tobacco consumption and potential instruments for policy interventions. According to Grossman's model of health capital ${ }^{42}$ and Becker and Murphy's model of rational addiction, ${ }^{43}$ smoking is the result of a bargain between the present satisfaction induced by tobacco consumption and the direct costs of tobacco, delayed losses induced by future tolerance, and potential losses in health capital. If the demand for tobacco is elastic to price variation, taxation is thus a natural incentive instrument for reducing tobacco consumption by increasing direct costs. This instrument has been shown to be efficient for reducing smoking initiation and for increasing tobacco cessation among pregnant women as well as in the general population of smokers. ${ }^{44}$ Despite tobacco taxation, the proportion of smokers remains higher in low-income than in high-income groups. While an increased price through taxes diminishes tobacco consumption among low-income individuals, it also raises equity concerns, as spending on tobacco has more weight in the budget of the low-income individual than in that of the high-income individual. In addition, it is difficult to implement for a targeted subpopulation. ${ }^{45} 46$

The updated meta-analysis of studies of financial incentive interventions in smoking cessation in the general population of smokers has shown that they increase cessation rates while they are in place. ${ }^{47}$ The meta-analysis of eight studies from the USA and UK among pregnant smokers provided an OR of $3.60(95 \%$ CI 2.39 to 5.43) favouring financial incentives over control conditions. ${ }^{47}$ Although evidence is growing to support the efficacy of financial incentives for smoking cessation among pregnant smokers, ${ }^{48}$ to the best of our knowledge, the data are from Anglo-Saxon countries with different cultural and healthcare system backgrounds from France.

On the other hand, a meta-analysis of various interventions (booklets, counselling, various psychotherapies, NRTs, financial incentives) to help pregnant smokers quit has shown a very modest overall effect on abstinence (relative risk (RR) $0.94 ; 95 \%$ CI 0.93 to 0.96). ${ }^{49}$

Among financial incentive studies in pregnant smokers, the study of Tappin et $a l^{\tilde{D}^{0}}$ has the highest power. Pregnant smokers were randomised into a control group (CG) and an intervention group (IG). The CG $(\mathrm{N}=306)$ received routine care: setting of a quit date, four-weekly phone calls, and 10 weeks of NRTs. The IG received routine care and financial incentives in the form of shopping vouchers up to $£ 400 \quad(\mathrm{~N}=306)$. 
The main outcome measure was point prevalence abstinence at gestational weeks $34-38$ verified by saliva or urinary cotinine. More pregnant smokers stopped smoking in the IG than in the CG $(22.5 \%$ vs $8.6 \%$; absolute risk difference $14 \%$ (95\% CI $8.2 \%$ to $19.7 \%)$ ). There was no difference in birth weight of their offspring (3140 g, $\mathrm{SD}=600$ vs $3120 \mathrm{~g}, \mathrm{SD}=590$ ).

The efficacy of financial incentives in helping pregnant smokers quit smoking has never been investigated in the French context. Because of cultural, economic and other individual and contextual differences, results from other countries cannot be directly applied to French pregnant smokers.

\section{BEHAVIOURAL CHARACTERISTICS AND SMOKING IN HEALTH ECONOMICS}

According to the seminal framework of behavioural economics of smoking, ${ }^{405152}$ time preferences are defined by how individuals weight future events when a decision involves delayed costs or benefits as well as present ones. The way individuals value time may affect present-day health decisions.

Experimental and health economic studies have reported that present-oriented individuals are more likely to be smokers than forward-looking ones, since present-oriented individuals overvalue the short-term satisfaction derived from smoking compared with future harmful consequences of tobacco smoking. ${ }^{41}$ On the basis of subjective scales introduced in the 2008 French National Health, Health Care and Insurance Survey (ESPS), Jusot and Khlat ${ }^{53}$ found that being presentoriented is associated with current smoking, even after adjustment for education. Regarding quitting behaviours, Brown and Adams ${ }^{54}$ provided evidence from Australian data that more-forward-looking individuals are more likely to quit smoking. A study based on the 2004 wave of the ESPS survey by Grignon ${ }^{55}$ reported that present-oriented individuals are more likely to quit after more failed attempts and at an older age.

The way individuals value risky outcomes-referred to as risk preference-may influence their likelihood of smoking. Empirical studies have found a negative relationship between risk aversion and tobacco use. ${ }^{53} 56$

The health psychology literature explains smoking cessation by various psychological determinants such as selfefficacy (ie, confidence in one's ability to abstain), impulsivity, locus of control, and personality traits. Self-efficacy is a determinant of smoking cessation in the sense that it is related to the likelihood of initiating and maintaining an effort and being able to cope with highly tempting situations (for a meta-analysis, see Gwaltney et $a \tilde{l}^{57}$ ). Since self-efficacy evolves during the cessation process, it needs to be assessed continuously during an intervention.

Choice impulsivity involves the preferential selection of smaller-sooner rewards over larger-later rewards. ${ }^{58}$ Hence, smokers choose the immediate benefits of cigarettes over a healthier future life. This attitude is usually associated with drug- and non-drug-related (eg, pathological gambling) addictions. Several studies have reported higher levels of impulsivity in smokers than in non-smokers. ${ }^{59}$ Impulsivity usually also predicts a shorter time of relapse because impulsive individuals are supposed to be more sensitive to smoking cues. ${ }^{60}$

Locus of control is related to the extent to which individuals believe that they can control what happens to them. The locus of control is to some degree internal (the individual believes she controls her life) or external (she believes that luck, fate or powerful others control her life). Abstinence from smoking is associated with an internally focused locus of control, such that individuals who perceive themselves as controlling life events are more likely to quit smoking. ${ }^{59}$

Personality traits from the five-factor model $^{61}$ (openness, conscientiousness, extraversion, agreeableness, neuroticism) have been shown to be associated with tobacco consumption. A meta-analysis ${ }^{62}$ has shown an association between smoking and low conscientiousness, low agreeableness and high neuroticism. Neuroticism is related to smoking, especially among individuals with low conscientiousness. Openness is significantly associated with motivation to quit and the number of quit attempts of 24 hours during the past year. ${ }^{63}$

Financial incentives may be especially efficient among women with particular socioeconomic and behavioural characteristics; they are expected to be particularly efficient among disadvantaged women who have a higher marginal utility of consumption than more advantaged ones. Similarly, providing immediate rewards for behaviour changes may help to reduce the effect of some behavioural characteristics such as immediacy and time preference. For instance, financial incentives may be more effective among present-oriented women who overvalue short-term satisfaction of smoking compared with future harmful consequences of tobacco smoking. Immediate financial incentives may neutralise the shortterm benefit of smoking by increasing the short-term benefit of smoking cessation.

\section{OBJECTIVES}

The main objective of this study is to assess the efficacy of financial incentives on smoking abstinence rate among French pregnant smokers.

Secondary objectives include exploration of predictors of response to financial incentives such as socioeconomic status, social background, smoking characteristics, locus of control, impulsivity, self-efficacy, personality traits, and time and risk preferences, in order to determine profiles of women who could be efficiently targeted by this kind of intervention. Further objectives include: (a) a costbenefit analysis based on the cost of pregnancy-related and infant-disease-related costs due to MSDP with respect to the cost and benefit of using financial incentives; (b) an assessment of selection bias from agreeing to being 
part of the study or not by comparing women who gave their consent to participate in the study and women who did not.

\section{METHODS AND ANALYSIS \\ Design}

This will be a single-blind, randomised, two parallel groups, national superiority trial run in 16 maternity wards all over France. A total of 398 pregnant smokers will be randomised (1:1 ratio) to the intervention $(\mathrm{N}=199)$ and control $(\mathrm{N}=199)$ groups.

\section{Participants}

Consent

Participants' written consent will be obtained by the investigators. In order for birth outcome data to be collected, participants will sign a statement to the effect that they are not opposed to recording of birth outcome data on the child to be born. These original documents will be archived by the investigators in their respective maternity wards.

\section{Inclusion criteria}

1. Pregnant women motivated to quit smoking (score higher than 5 on a visual analogue scale ranging from 0 (not at all motivated) to 10 (extremely motivated)).

2. 18 years old or older.

3. Smoking at least five cigarettes per day or three roll-your-own cigarettes per day.

4. Pregnancy of $<18$ weeks of amenorrhoea (WA).

5. Affiliated to National Health Insurance funds or to another medical health insurance fund as required by French law on biomedical research.

6. Having signed an informed written consent form

7. Agreeing to collection of birth characteristics of the child to be born.

\section{Exclusion criteria}

1. Current treatment for a chronic psychiatric disorder using neuroleptics, antidepressants or anxiolytics.

2. Use of tobacco products other than cigarettes.

3. Use of either bupropion or varenicline because their use is contraindicated in pregnancy.

4. Because of the lack of knowledge on the health benefit-risk ratio of electronic cigarettes, ${ }^{64}$ electronic cigarette users will be excluded.

NB Multiple pregnancies will not be an exclusion criterion.

\section{Setting and recruitment}

Participants will be recruited, included and followed-up in 16 maternity wards in France. The 16 centres are expected to include 20-30 smoking pregnant women every month. Assuming that each centre will randomise 15 women per year, we will be able to recruit 240 women per year.
Participants will be recruited by word of mouth, flyers and advertisements in pharmacies, local radio broadcasts, local newspapers, general practitioner offices and in the participating maternity wards. After a phone interview for eligibility, pregnant smokers will be invited to attend the closest maternity ward for a screening visit.

Investigators will be midwifes or physicians who routinely treat pregnant smokers. They should all have obtained a smoking cessation specialist diploma and should be familiar with smoking cessation issues among pregnant smokers.

\section{Randomisation}

A computer-generated randomisation list in blocks of four will be prepared by a statistician who is independent of the study. The randomisation list by centre will be incorporated into the electronic case report form (eCRF). A randomisation number will be allocated at the first visit after the participants' characteristics have been checked for inclusion/exclusion criteria and their written informed consent obtained.

\section{Interventions}

During each visit, each woman will benefit from a short intervention for smoking cessation according to nationally accepted guidelines whatever the study group they belong to. It will include motivational counselling, support and skill-training elements. ${ }^{6566}$

All necessary care and interventions will be permitted during the trial.

\section{Chronology of the trial}

A quit date will be set at randomisation. The quit date should occur between randomisation and day 14 . Monthly face-to-face visits will be planned. The total number of visits will depend on the date of delivery. For example, if the quit date is at $12 \mathrm{WA}$ and delivery at $40 \mathrm{WA}$, monthly visits will be carried out at WA 16,20 , 24, 28, 32 and 36 (six visits); if the quit date is at $16 \mathrm{WA}$ and delivery at $34 \mathrm{WA}$, four visits will be conducted (WA 20, 24, 28 and 32). The number of visits determines the amount of monetary rewards earned for attending the visits in both groups. The total duration of participation in the study will be 12 months on average: $~ 6$ months until giving birth and a follow-up phone call 6 months after birth.

In cases of missed visits, participants will be called by telephone at least twice, followed, in the case of nonresponse, by regular mail to encourage them to attend the next visit.

\section{Incentives for abstinence}

Monetary reward for abstinence will be given through vouchers (Kadeos http://www.edenred.fr/besoin/avantagesaux-salaries/produit/ticket-kadeos/) that can be redeemed in many different shops and superstores; they cannot be used to buy tobacco or alcohol products. The value of each voucher will be €20. Participants in both control 
and intervention groups will receive a $€ 20$ voucher as a show-up fee for completing the visit.

\section{Intervention group (IG)}

Every participant can earn additional vouchers conditional on her abstinence. For example, if the participant has abstained during five consecutive visits, she can earn up to $€ 380$ of vouchers.

Figure 1 shows the payoff tree (in euros) that a participant can earn according to her group and abstinence, under the assumption that she attends five visits.

In the IG, the payoffs are based on two principles: the reward for abstinence today and the reward for continuous (past) abstinence. Hence, the payoff increases with the number of times a participant has been abstinent but also with the number of successive abstinences.

If the participant is not abstinent $(\overline{\mathrm{A}})$, she gets a $€ 20$ voucher as a show-up fee. If she is abstinent (A), she earns the show-up fee and an additional amount to reward her abstinence. If she is abstinent at the first postquit day visit she will be rewarded with an additional $€ 40$ of vouchers. This amount then increases by $€ 20$ progressively if she remains abstinent for the next visits (€60, $€ 80$ and $€ 100$ ). If a participant has been abstinent and then non-abstinent, the next time she is abstinent, the last abstinent payment will recur in order to reward her abstinence and avoid penalty for the previous nonabstinence. This feature also helps to reduce no-show, especially if the participant has been abstinent. Table 1 refers to four different scenarios of financial incentives (in euros) according to the abstinence of the participant over five visits.

If a participant does not show up for a visit but shows up for the next visit, the no-show-up visit will be considered to be a non-abstinence visit, and therefore when she shows up at the next visit, the financial incentive will be that of the last show-up visit.

A general expression allows us to determine the total payoffs after the total number of visits, $\mathrm{T}$, according to each situation. Let $Y_{\mathrm{T}}^{\mathrm{IG}}$ be the total payoff after $\mathrm{T}$ visits in the IG

$$
\begin{aligned}
& \mathrm{Y}_{\mathrm{T}}^{\mathrm{IG}}=20+\left[40 \cdot \mathrm{N}_{2}^{\mathrm{A}} \cdot \mathrm{I}_{2}^{\mathrm{A}}+20\right]+\sum_{\mathrm{t}=3}^{\mathrm{T}}\left(20 \cdot \mathrm{I}_{\mathrm{t}}^{\mathrm{A}} \cdot\left(\mathrm{N}_{\mathrm{t}}^{\mathrm{A}}+1\right)+20\right) \\
& \quad \text { for } \mathrm{t}=\{3, \ldots, \mathrm{T}\}
\end{aligned}
$$

The first visit is the inclusion and randomisation visit in both groups and everyone receives $€ 20 . \mathrm{N}_{t}^{\mathrm{A}}$ is the number of successive times a pregnant woman has been abstinent, measured at visit $t . \mathrm{I}_{\mathrm{t}}^{\mathrm{A}}$ is a dummy variable, which is equal to 1 if the pregnant woman is abstinent at visit $\mathrm{t}$, and is equal to 0 otherwise.

\section{Control group (CG)}

Participants randomised to the CG will receive a $€ 20$ voucher at the end of each completed visit as a show-up fee, but in contrast with the IG, abstinence will not be rewarded. The total payoff will be a function of the total number of visits the participant attended.

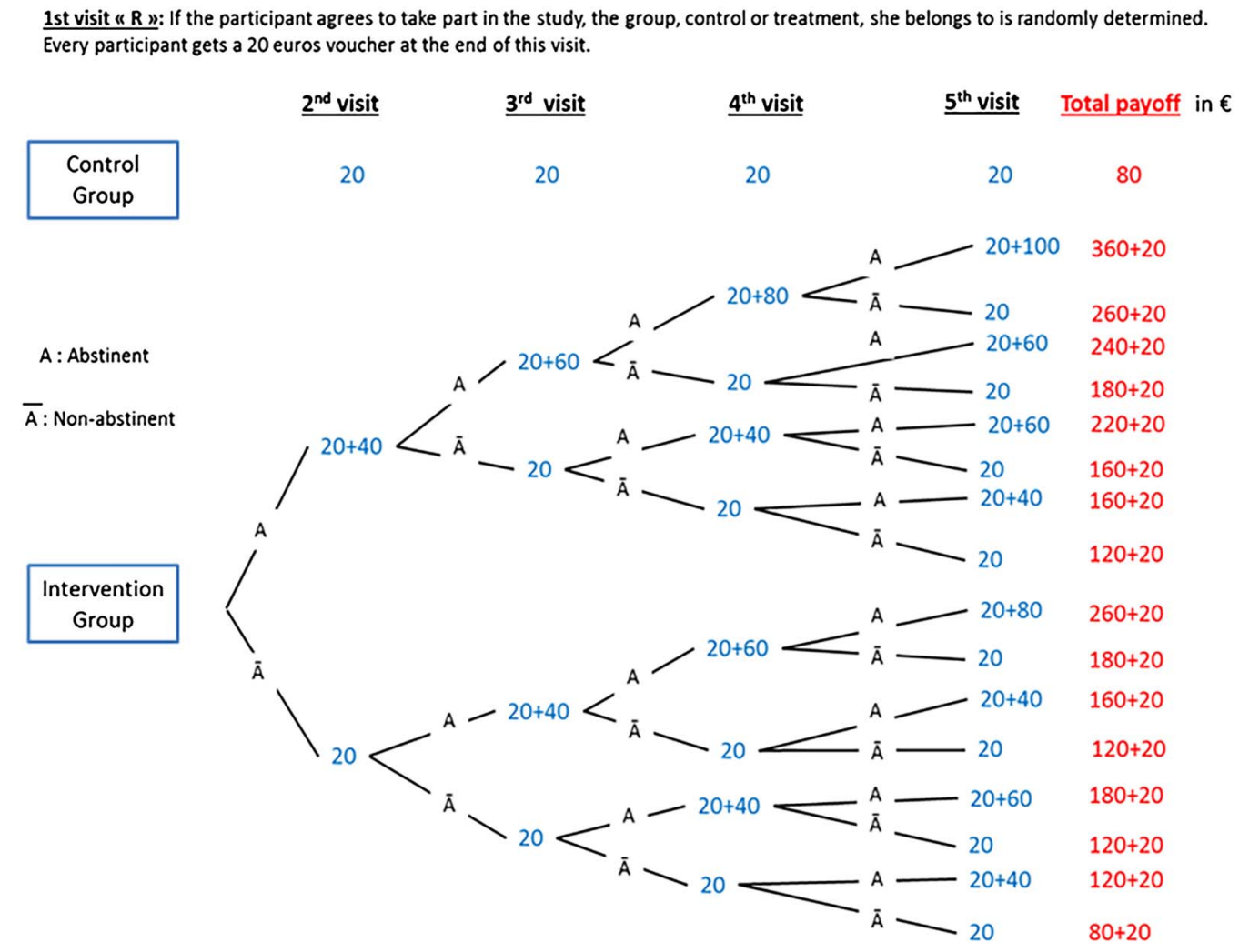

Figure 1 Payoff tree for both the intervention (contingency management) and control groups. 
Table 1 Four examples of financial incentives in euros according to abstinence $(A) /$ non-abstinence $(\bar{A})$ of pregnant women at study visits $(V)$

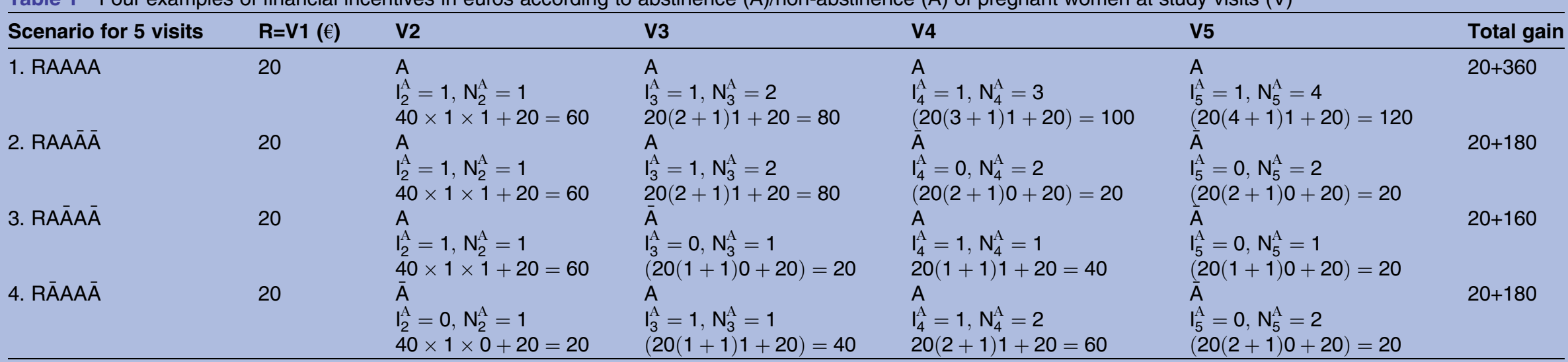

$\mathrm{Y}_{\mathrm{T}}^{\mathrm{IG}}=20+\left[40 \mathrm{~N}_{2}^{\mathrm{A}} \mathrm{I}_{2}^{\mathrm{A}}+20\right]+\sum_{\mathrm{t}=3}^{\mathrm{T}}\left(20 \mathrm{I}_{\mathrm{t}}^{\mathrm{A}}\left(\mathrm{N}_{\mathrm{t}}^{\mathrm{A}}+1\right)+20\right) \quad$ for $\mathrm{t}=\{3, \ldots, \mathrm{T}\}$.

The first scenario RAAA refers to a participant who was randomised to the intervention group (IG) during the first visit and was abstinent in the following four visits. Hence, during the second visit ( $\mathrm{t}=2$ ), she would get a $€ 20$ voucher for showing up plus a $€ 40$ voucher for being abstinent (because she is abstinent $I_{2}^{A}=1$ and because it's the first time since randomisation she's being checked for being abstinent, then $\left.N_{2}^{A}=1\right)$. At the last visit $(t=5)$, showing up and being abstinent $\left(I_{5}^{A}=1\right)$ for the fourth time $\left(N_{5}^{A}=4\right)$ yields a voucher of $20+20(4+1) 1=€ 120$.

The second scenario RAAĀA refers to a participant who was randomised to the IG during the first visit and abstinent at the 2 nd and 3rd visits, and non-abstinent at the 4th and 5th visits. Hence, for the second visit, the abstinent participant would receive the $€ 20$ voucher show-up fee plus the $€ 40$ voucher for being abstinent $\left(I_{2}^{A}=1\right.$ and $\left.N_{2}^{A}=1\right)$. At the third visit, by showing up she

would get the $€ 20$ voucher, and by being abstinent $\left(I_{3}^{A}=1\right)$ for the second consecutive time $\left(N_{3}^{A}=2\right)$, she would receive an additional $€ 20(2+1) 1=€ 60$ voucher, etc.

If one looks at scenario 4, the participant is being randomised to the IG at the first visit, then is not abstinent at the 2nd visit, abstinent at the 3rd and 4th visits, and not abstinent at the 5 th visit. Hence, during visit 4 , for example, she would receive the $€ 20$ voucher for showing up, and, by being abstinent $\left(1_{4}^{\mathrm{A}}=1\right)$ for the second consecutive time $\left(\mathrm{N}_{4}^{\mathrm{A}}=2\right)$, she would get a $€ 20 \times(2+1) \times 1=$ $€ 60$ voucher. However, as in the 5 th visit she is not abstinent, she then gets the $€ 20$ show-up voucher.

$\mathrm{R}$, randomisation visit, $\mathrm{V} 1$. 
Hence, the total payoff for participants in the CG is

$$
\mathrm{Y}_{\mathrm{T}}^{\mathrm{GC}}=20 \cdot \mathrm{t}, \quad \text { for } \mathrm{t}=\{1, \ldots, \mathrm{T}\}
$$

\section{Outcomes}

\section{Main outcome measure}

The main outcome measure will be the continuous smoking abstinence from the predefined quit date until the last predelivery visit.

Previous studies were mainly interested in whether smoking reduction is associated with reduced birth weight. Two earlier studies ${ }^{67} 68$ reported that smoking reduction among pregnant smokers had no impact on birth weight. Two subsequent studies ${ }^{69}{ }^{70}$ have shown that reduced cigarette consumption decreased but did not nullify smoking-related loss in birth weight. At the public health level, even a small reduction in a population's birth weight may have long-lasting consequences for the offspring. Continuous abstinence since quit date has a higher likelihood of suppressing smoking-related loss in birth weight than smoking reduction. For this reason, continuous abstinence since quit date has been chosen as the main outcome measure.

\section{Secondary outcome measures}

For mothers:

- Point prevalence abstinence at visits defined as selfreported no smoking in the last 7 days and expired air carbon monoxide $\leq 8 \mathrm{ppm}$.

- Time (days) to first cigarette after quit date (lapse (a few puffs) or relapse).

- Total number of cigarettes smoked per day.

- Craving to smoke and withdrawal symptom scores.

For newborns:

- Birth weight and other birth characteristics such as head circumference, length, Apgar score at 5 min.

- Gestational age at birth.

- Assessment of intrauterine growth restriction calculated by AUDIPOG (http://www.augipog.net), a national network of intrauterine growth data.

Negative health outcomes during pregnancy (maternal and fetal) and at birth will be recorded from clinical charts.

\section{Power calculation}

A previous study ${ }^{38}$ that compared nicotine patches with placebo patches in pregnant smokers has shown a continuous abstinence rate of $5.5 \%$ in the nicotine group vs $5.1 \%$ in the placebo group. Some $53 \%$ of women in the nicotine group did not show up for every visit compared with $62 \%$ in the placebo group. In Tappin et al, ${ }^{50}$ more smokers who were provided with financial incentives $(22.5 \%)$ had stopped smoking than in the nonincentivised group $(8.6 \%)$. It is noteworthy that, in this study, the main outcome measure was point prevalence abstinence at 34-38 WA and not continuous abstinence as in the present study.
Table 2 Power calculation for the number of participants needed to demonstrate a statistically significant difference in the main outcome measure with a randomisation ratio of $1: 1$

\begin{tabular}{llll}
\hline$\alpha$ & & $\begin{array}{l}\text { N for control } \\
\text { group }\end{array}$ & $\begin{array}{l}\text { N for intervention } \\
\text { group }\end{array}$ \\
\hline
\end{tabular}

1. Two-sided hypothesis: abstinence rate $=10 \%$

in the control group and $=25 \%$ in the intervention group

$\begin{array}{llll}0.05 & 0.90 & 133 & 133\end{array}$

$\begin{array}{llll}0.05 & 0.85 & 114 & 114\end{array}$

$\begin{array}{llll}0.05 & 0.80 & 100 & 100\end{array}$

2. Two-sided hypothesis: abstinence rate $=10 \%$

in the control group and $=20 \%$ in the intervention group

$\begin{array}{llll}0.05 & 0.90 & 266 & 266\end{array}$

$\begin{array}{llll}0.05 & 0.85 & 228 & 228\end{array}$

$\begin{array}{llll}0.05 & 0.80 & 199 & 199\end{array}$

The power calculation is based on the main outcome measure. We assume that the abstinence rate among pregnant women will be $10 \%$ in the CG and either $25 \%$ or $20 \%$ in the IG, as presented in table 2 . We hypothesise a $10 \%$ continuous abstinence rate, double that previously observed $^{38}$ in the CG because of the financial reward of showing-up, which may in itself increase the abstinence rate by increasing show-ups. According to table 2 , assuming a $20 \%$ abstinence rate in the IG, a conservative approach, with an $\alpha=0.05$ and $1-\beta=0.80$, we would need to randomise 199 women to each group.

In Tappin et al, ${ }^{50}$ the lost-to-follow-up rate is $14 \%$ and $15 \%$ at the primary end point of gestational weeks 34-38. Because of the high frequency (monthly) of face-to-face visits and because show-ups are rewarded with $€ 20$, we assume an overall dropout rate of $5 \%$, implying that we would need to randomise 420 pregnant smokers. We assume that approximately 40 women by group will not show up for the first visit, and as a consequence, we expect to recruit between 460 and 480 women who signed the informed consent forms to finally randomise 420 .

\section{Independent variables}

1st visit:

- Demographic, socioeconomic, obstetric and smoking characteristics

- Age

- Household income

- Self-reported ethnic origin

- Medical, psychiatric history

- Obstetric history: number of previous pregnancies, abortions, miscarriages, deliveries, premature delivery, number of children

- Weeks of amenorrhoea

- Smoking history and characteristics

- Age smoked first cigarette

- Partner's smoking

- Second-hand smoke exposure 
- Number of cigarettes smoked during the last 7 days

- Fagerström Test for Cigarette Dependence ${ }^{71}$

- Craving for tobacco using French Tobacco Craving Questionnaire (FTCQ-12)

- Withdrawal Symptoms Questionnaire 7374

- Expired air CO concentration (Smokerlyzer; Bedfont, Maidstone, Kent, UK)

- Cannabis consumption in the last 30 days

- Alcohol consumption in the last 30 days

- Evaluation of alcohol dependence

(CAGE questionnaire $)^{75}$

- Current use of psychotropic medications

- Weight $(\mathrm{kg})$ and height $(\mathrm{cm})$

- Sitting systolic and diastolic blood pressure

Behavioural measures:

- Time preferences: the subjective scale from ESPS and the scale for consideration of future consequences (validated measure in French) ${ }^{53}$

- Risk preferences: a subjective scale tested and validated in the ESPS survey which measures the willingness to take risks. We will also use a measure developed by Dohmen et $a l^{76}$ which measures risk aversion in domain-specific risks (financial, health, social)

- Impulsivity: Barratt Impulsivity Scale ${ }^{77}$ - validated French version $^{78}$

- Locus of control: Fetal Health Locus of Control (FHLC) created and validated by Labs and Wurtele. ${ }^{79}$ To guarantee validity, this measure will be administered twice: once at inclusion (visit 1) and once halfway through the study (visit 3)

- Big Five personality test: ${ }^{60} 78$ a short $(<1$ min to complete) assessment of personality traits, such as extraversion, conscientiousness, agreeableness, neuroticism and openness to experience

A urine sample will be collected to quantify concentration of anabasine, anatabine and cotinine. The justification for this is as follows. Nicotine accounts for $\sim 85-$ $95 \%$ of the alkaloid content of tobacco, while anabasine and anatabine are among the most abundant minor tobacco alkaloids. ${ }^{80}$ Owing to the relatively short elimination half-life of nicotine (about 2 hours), investigating nicotine metabolites that exhibit a longer half-life is a prerequisite to providing relevant information on tobacco consumption. Cotinine is the main metabolite of nicotine whose mean elimination half-life can be shorter during pregnancy. Tobacco use increases the urinary concentration of all three compounds. Complete abstinence from tobacco or no use of NRTs is associated with $<3 \mathrm{ng} / \mathrm{mL}$ urinary anabasine and $<10 \mathrm{ng} / \mathrm{mL}$ urinary anatabine. The measure of non-nicotinic alkaloids allows us to distinguish no tobacco use from NRT use, which is associated with urinary cotinine concentration $>10 \mathrm{ng} /$ $\mathrm{mL}$. A pregnant woman will therefore be considered not to be smoking and not receiving NRT if she reports no smoking and her expired air CO is $\leq 8 \mathrm{ppm}$, her urinary anabasine is $\leq 3 \mathrm{ng} / \mathrm{mL}$ and her urinary cotinine is $\leq 10 \mathrm{ng} / \mathrm{mL}$. Because anatabine's cut-off values are less well established, its determination will not be used in the primary assessment of abstinence. Quantification of the three compounds in urine samples will be performed by ultra-high performance liquid chromatography coupled with tandem mass spectrometry after a dedicated sample preparation procedure. ${ }^{82} 83$

Follow-up visits: 2 nd to last visit (visit 5 or 6 ):

- Self-reported smoking status (abstinent or not) and expired air $\mathrm{CO}$

- Number of cigarettes smoked in the last 7 days

- Use of NRT: type and daily dose

- Use (or not) of an electronic cigarette

- FTCQ-12

- Withdrawal Symptoms Questionnaire

- Cannabis consumption in the last 30 days

- Alcohol consumption since last visit: Yes/No

- Weight

- Sitting systolic and diastolic blood pressure

- Any negative health event related or not to the pregnancy. At visit 3, participants will be asked to complete a short questionnaire including the FHLC

- Urine sample: as mentioned above, one urine sample will be collected during the inclusion visit (visit 1). A second sample will be randomly collected at visit 2, 3 or 4 according to a random list included in the eCRF. The post-quit day urine sample will allow us to control for self-reported abstinence

Postpartum follow-up: 6 months:

Participants will be contacted 6 months after delivery for a phone interview. This follow-up survey will record data about the child's evolution, about the smoking status of the mother and the partner, breastfeeding, satisfaction about the intervention, marital and employment status, and an assessment of stress since delivery. ${ }^{84}$

\section{Data management}

Data will be entered into the eCRF using CleanWEB software with range checks for data values. Source documents will be kept by the investigation centres (maternity wards). Data recorded in the eCRF will be doublechecked by a research monitoring assistant. This research complies with the law of 6 January 1978 article 54 and was declared to the Commission nationale de l'informatique et des libertés (CNIL) (https://www.formulaires. modernisation.gouv.fr/gf/cerfa_13810.do). All data will be recorded anonymously using the centre number (three digits), randomisation number (four digits) and the first letter of the participants' name and surname.

\section{DATA ANALYSIS}

Outcomes will be analysed on an intention-to-treat (ITT) basis. The ITT population is defined as all randomised smoking pregnant women. The completer population will be defined as the population that completed all visits.

Participants who do not show up at a visit will be considered to be smoking (non-abstinent) for this missed visit. 
Smoking relapse or multiple missed visits will not be a criterion for dropout. Participation in the study ends if pregnancy ends (delivery or any other reasons such as miscarriage). Data of a participant who withdraws her consent to participate will not be included in the ITT database.

\section{Main analysis}

The main outcome measure for the mother will be complete continuous abstinence since the quit date, which will be defined as abstinence at each visit (self-reported abstinence during the last 7 days and expired air $\mathrm{CO} \leq 8 \mathrm{ppm}$ ) from randomisation to delivery (ie, last study visit before delivery). Abstinence rates will be compared between the intervention and control groups using Fisher's exact test.

\section{Secondary analyses}

Relapse to smoking will be described by Kaplan-Meier curves and compared with the log-rank test.

Multivariate analyses will be performed to evaluate the determinants of continuous abstinence since quit date to delivery. Control variables for the intervention effect will be the sociodemographic, tobacco-related, psychological and behavioural characteristics, duration and total dose of NRTs, and centres.

The analysis will include interacting subgroup characteristics such as, for instance, how this probability varies for low and highly educated women who are strongly present-oriented.

The first questionnaire that will be filled in by women taking part in the study and those who do not will provide an insight into the selection bias to participate in the study.

No interim analysis is planned. Unlike medications, financial incentives-the intervention assessed by this trial—cannot lead to premature stopping of the study because of adverse health outcomes.

\section{Sensitivity analyses}

1. Differences between intervention and control groups for both main and secondary outcomes will also be analysed according to biochemical verification of abstinence based on negative anabasine, self-report of no smoking, and expired air $\mathrm{CO} \leq 8 \mathrm{ppm}$.

2. A second sensitivity analysis of efficacy will be run in which participants with missing visit(s) will be imputed as smokers versus imputing non-smoking if a participant misses a visit between two visits for which she was abstinent.

\section{Ancillary analysis}

The diagnostic validity of urinary anabasine and anatabine for abstinence will be assessed (sensitivity, specificity, negative and positive prognostic value).

\section{Analysis of adverse pregnancy outcomes}

It cannot be assumed that financial incentive interventions contribute to adverse pregnancy and/or birth outcomes. However, it can be hypothesised that an increased abstinence rate in the financial incentive group may reduce adverse pregnancy and birth outcomes.

Adverse pregnancy outcomes such as premature birth, miscarriage, abortion (medical or voluntary), stillbirth, caesarean section, haemorrhage at delivery, newborn's transfer to neonatal intensive care unit will be recorded and tabulated by group in a descriptive manner. Because the intervention cannot lead to adverse health effects, no safety monitoring committee will be implemented.

\section{DISCUSSION}

In this study, we will investigate the effect of financial incentives on smoking cessation and abstinence during pregnancy with the hypothesis that financial rewarding of abstinence (IG) compared with the lack of financial incentive (CG) will increase the abstinence rate. Face-to-face monthly visits are planned up to delivery. Showing up to visits will be rewarded with $€ 20$ with the hope that it will increase attendance.

One previous study has shown improved abstinence rate as the result of financial incentives ${ }^{50}$ among British pregnant smokers. However, major cultural differences and the potentially higher acceptability of financial incentives for rewarding abstinence in pregnant smokers in France than in the UK means that such an intervention needs to be tested in this target population.

An increased continuous rate of abstinence resulting from financial incentives may improve pregnancy and birth outcomes, in particular birth weight, much more than occasional point prevalence abstinence because it may suppress or at least reduce tobacco-associated intrauterine growth restriction. Compared with intermittent, point prevalence abstinence, continuous complete abstinence may have a greater public health impact. Identification of socioeconomic and behavioural predictors of outcome will help to characterise specific subgroups that respond better to financial incentives.

\section{Cost-benefit analysis}

A cost-benefit analysis will be undertaken after the completion of the trial. It will use costs related to pregnancy when the mother smoked during pregnancy compared with the costs of implementing financial incentives, ${ }^{85}$ but it will also include costs related to postnatal infant health disorders (such as wheezing, asthma, psychiatric and metabolic disorders) whose risk factors include MSDP.

\section{Trial management}

The Coordinating Centre at the Hôpital Pitié-Salpêtrière, Université P. and M. Curie Faculté de medicine, Département de pharmacologie and Unité de recherche clinique takes responsibility for all aspects of the study: ethical, regulatory, study conduction, data-management and publication strategy. It will supervise and coordinate the realisation of the trial and be in continuous contact with the study's centres (maternity wards). 
Coordinating Centre Members: Chair, Ivan Berlin; data management, Leontine Goldzahl; medicoeconomics, Noémi Berlin and Florence Jusot; monitoring and administration, Jessica Palmyre, France Boyaud and Shoreh Azimi.

No drug safety monitoring committee will be established.

\section{ETHICS AND DISSEMINATION}

As dictated by French law on biomedical research, all participants can withdraw from the study at any time and without any justification. The research protocol was approved by the ethics committee (Comite de Protection des Personnes, CPP) of the Pitié-Salpêtrière Hospital on 15 May 2015. Amendment No 1 was approved on 13 July 2015. A consent form in French is available upon request.

Results will be presented at scientific meetings. The authors commit themselves to publish all results of this study in medical, health economic or other scientific journals. The data will be the property of the sponsor, the Assistance public-Hôpitaux de Paris (APHP). The disposition of data sharing and data deposition will be defined by the sponsor.

Acknowledgements We thank Dr Raul Nicoli and Professor Martial Saugy of the Swiss Laboratory for Doping Analyses, Centre Hospitalier Universitaire Vaudois (CHUV) and Université de Lausanne for their help, including urinary measures of anabasine, anatabine and cotinine.

Contributors All the authors substantially contributed to the conception and the design of the work. The first version of the manuscript was drafted by NB she conceived the financial incentive algorithm which was discussed and approved by the other authors. IB applied for funding and conceived and drafted the medical parts of the work, while NB, LG and FJ conceived and drafted the financial and health economic parts of the work. All the authors drafted the data analysis section and revised the work critically for important intellectual content and gave final approval of the version submitted.

Funding This work was supported by the Institut du Cancer, France (grant 'Prévention Primaire' number 2014-100). Sponsor: Assistance public-Hôpitaux de Paris (APHP) http://www.aphp.fr, Département de la Recherche Clinique et Développement (study number: P140106). Neither funder nor sponsor had any role in the study design, writing of this report, or the decision to submit the report for publication.

Competing interests $L G$ is a postdoctoral fellow partially funded by the grant 'Prévention Primaire' number 2014-100. IB received honoraria from Pfizer and Novartis for delivering educational presentations and participation in advisory boards in the last 3 years.

Ethics approval Comité de Protection des Personnes of the Pitié-Salpêtrière Hospital on 15 May 2015.

Provenance and peer review Not commissioned; externally peer reviewed.

Open Access This is an Open Access article distributed in accordance with the Creative Commons Attribution Non Commercial (CC BY-NC 4.0) license, which permits others to distribute, remix, adapt, build upon this work noncommercially, and license their derivative works on different terms, provided the original work is properly cited and the use is non-commercial. See: http:// creativecommons.org/licenses/by-nc/4.0/

\section{REFERENCES}

1. Jusot F, Tubeuf S, Trannoy A. Circumstances and efforts: how important is their correlation for the measurement of inequality of opportunity in health? Health Econ 2013;22:1470-95.

2. Etilé $F$, Jones AM. Schooling and smoking among the baby boomers -an evaluation of the impact of educational expansion in France. $\checkmark$ Health Econ 2011;30:811-31.
3. Bur Y. Proposition pour une nouvelle politique de lutte contre le tabac. 2012. http://www.sante.gouv.fr/rapport-de-yves-burproposition-pour-une-nouvelle-politique-de-lutte-contre-le-tabac.htm

4. Jacquat D, Touraine J. Rapport d'information sur l'evaluation des politiques publiques de lutte contre le tabagisme. 2013. http://www assemblee-nationale.fr/14/rap-info/i0764.asp

5. Cour des comptes. Rapport d'évaluation des politiques de lutte contre le tabagisme. http://societe-francaise-de-tabacologie.com/dl/ CourComptes-tabagisme2012.pdf

6. Kopp P. Le coût social des drogues en France. OFDT Note 2015-04 http://www.ofdt.fr/BDD/publications/docs/eisxpkv9.pdf

7. Nilsson PM, Hofvendahl S, Hofvendahl E, et al. Smoking in pregnancy in relation to gender and adult mortality risk in offspring: the Helsingborg Birth Cohort Study. Scand J Public Health 2006;34:660-4.

8. Knopik VS, Maccani MA, Francazio S, et al. The epigenetics of maternal cigarette smoking during pregnancy and effects on child development. Dev Psychopathol 2012;24:1377-90.

9. The health consequences of smoking -50 years of progress: a report of the surgeon general, 2014. http://www.surgeongeneral. gov/library/reports/50-years-of-progress/ (accessed 9 Apr 2015).

10. Buka SL, Shenassa ED, Niaura R. Elevated risk of tobacco dependence among offspring of mothers who smoked during pregnancy: a 30-year prospective study. Am J Psychiatry 2003;160:1978-84.

11. Ekblad M, Gissler M, Lehtonen L, et al. Prenatal smoking exposure and the risk of psychiatric morbidity into young adulthood. Arch Gen Psychiatry 2010;67:841-9.

12. Burke $\mathrm{H}$, Leonardi-Bee J, Hashim A, et al. Prenatal and passive smoke exposure and incidence of asthma and wheeze: systematic review and meta-analysis. Pediatrics 2012;129:735-44.

13. Oken E, Levitan EB, Gillman MW. Maternal smoking during pregnancy and child overweight: systematic review and metaanalysis. Int J Obes 2008;32:201-10.

14. Berlin I. Retentissement postnatal du tabagisme pendant la grossesse. Collège National des Gynécologues et Obstetriciens Français. Mises à jour en Gynécologie Médicale. 2010:205-10.

15. Doherty SP, Grabowski J, Hoffman C, et al. Early life insult from cigarette smoke may be predictive of chronic diseases later in life. Biomarkers 2009;14 (Suppl 1):97-101.

16. Stavrou EP, Baker DF, Bishop JF. Maternal smoking during pregnancy and childhood cancer in New South Wales: a record linkage investigation. Cancer Causes Control 2009;20:1551-8.

17. Brooks DR, Mucci LA, Hatch EE, et al. Maternal smoking during pregnancy and risk of brain tumors in the offspring. A prospective study of 1.4 million Swedish births. Cancer Causes Control 2004;15:997-1005.

18. Mucci LA, Granath F, Cnattingius S. Maternal smoking and childhood leukemia and lymphoma risk among 1,440,542 Swedish children. Cancer Epidemiol Biomarkers Prev 2004;13:1528-33.

19. Ferreira J. Pregnancy, maternal tobacco smoking, and early age leukemia in Brazil. Front Oncol 2012;2:151.

20. Enquète national périnatal. http://www.sante.gouv.fr/IMG/pdf/Les naissances en 2010 et leur_evolution depuis_2003.pdf (accessed 5 Nov 2015).

21. Institut national de la statistique et des études économiques, Insee -Population-Statistiques d'état civil sur les naissances en 2010. http://www.insee.fr/fr/themes/document.asp?ref_id=sd20101 (accessed 1 Apr 2016).

22. Lelong N, Kaminski M, Saurel-Cubizolles MJ, et al. Postpartum return to smoking among usual smokers who quit during pregnancy. Eur J Public Health 2001;11:334-9.

23. Letourneau AR, Sonja B, Mazure CM, et al. Timing and predictors of postpartum return to smoking in a group of inner-city women: an exploratory pilot study. Birth 2007;34:245-52.

24. Lauria L, Lamberti A, Grandolfo M. Smoking behaviour before, during, and after pregnancy: the effect of breastfeeding. ScientificWorld Journal 2012;2012:154910.

25. Jones M, Lewis S, Parrott S, et al. Re-starting smoking in the postpartum period after receiving a smoking cessation intervention: a systematic review. Addiction 2016;111:981-90.

26. Stead LF, Perera R, Bullen C, et al. Nicotine replacement therapy for smoking cessation. Cochrane Database Syst Rev 2012;(11): CD000146.

27. Traitements de Substituts Nicotiniques (TSN) et femmes enceintes -ANSM: Agence nationale de sécurité du médicament et des produits de santé. http://ansm.sante.fr/S-informer/PresseCommuniques-Points-presse/Traitements-de-SubstitutsNicotiniques-TSN-et-femmes-enceintes/\%28language\%29/fre-FR (accessed 9 Apr 2015).

28. National Institute for Health and Care Excellence. NICE. Smoking: stopping in pregnancy and after childbirth. http://www.nice.org.uk/ 
guidance/PH26/chapter/1-Recommendations\#recommendation-5-useof-nrt-and-other-pharmacologicalsupport (accessed 19 Feb 2016).

29. Treating Tobacco Use and Dependence: 2008 Updatetreating tobacco use08.pdf. http://www.ahrq.gov/professionals/ clinicians-providers/guidelinesrecommendations/tobacco/clinicians/ update/treating_tobacco_use08.pdf (accessed 9 Apr 2015).

30. Wisborg K, Henriksen TB, Jespersen LB, et al. Nicotine patches for pregnant smokers: a randomized controlled study. Obstet Gynecol. 2000;96:967-71.

31. Kapur B, Hackman R, Selby P, et al. Randomized, double-blind, placebo controlled trial of nicotine replacement therapy in pregnancy. Curr Ther Res Clin Exp 2001;62:274-8.

32. Hotham ED, Gilbert AL, Atkinson ER. A randomised-controlled pilot study using nicotine patches with pregnant women. Addict Behav 2006;31:641-8.

33. Pollak KI, Oncken CA, Lipkus IM, et al. Nicotine replacement and behavioral therapy for smoking cessation in pregnancy. Am J Prev Med 2007;33:297-305.

34. Oncken C, Dornelas E, Greene J, et al. Nicotine gum for pregnant smokers: a randomized controlled trial. Obstet Gynecol 2008:112:859-67.

35. Coleman T, Chamberlain C, Cooper S, et al. Efficacy and safety of nicotine replacement therapy for smoking cessation in pregnancy: systematic review and metaanalysis. Addiction 2011;106:52-61.

36. Coleman T, Chamberlain C, Davey M-A, et al. Pharmacological interventions for promoting smoking cessation during pregnancy. Cochrane Database Syst Rev 2012;(9):CD010078.

37. Coleman T, Cooper S, Thornton JG, et al. A randomized trial of nicotine-replacement therapy patches in pregnancy. N Engl J Med 2012;366:808-18

38. Berlin I, Grangé G, Jacob N, et al. Nicotine patches in pregnant smokers: randomised, placebo controlled, multicentre trial of efficacy. BMJ 2014;348:g1622.

39. Coleman T, Chamberlain C, Davey M-A, et al. Pharmacological interventions for promoting smoking cessation during pregnancy. Cochrane Database Syst Rev 2015;(12):CD010078.

40. Chaloupka FJ, Warner KE. Chapter 29 The economics of smoking. Handb Heal Econ 2000;1:1539-627.

41. Cawley J, Ruhm CJ. The economics of risky health behaviors. Handb Heal Econ 2011;2:95-199.

42. Grossman M. On the concept of health capital and the demand for health. J Polit Econ 1972;80:223-55.

43. Becker GS, Murphy KM. Theory of rational addiction. J Polit Econ 1988;96:675-700.

44. Grignon M, Reddock J. The effect of interventions targeting tobacco consumption: a review of literature reviews. Quest. d'économie la santé 2012;182:1-8.

45. Godefroy R. Les taxes sur les cigarettes sont-elles régressives? Économie publique/Public Econ 2003;13:3-28.

46. Colman GJ, Remler DK. Vertical equity consequences of very high cigarette tax increases: If the poor are the ones smoking, how could cigarette tax increases be progressive? J Policy Anal Manag 2008;27:376-400.

47. Cahill K, Hartmann-Boyce J, Perera R. Incentives for smoking cessation. Cochrane Database Syst Rev 2015;(5):CD004307.

48. Higgins ST, Solomon LJ. Some recent developments on financial incentives for smoking cessation among pregnant and newly postpartum women. Curr Addict Rep 2016;3:9-18.

49. Lumley J, Chamberlain C, Dowswell T, et al. Interventions for promoting smoking cessation during pregnancy. Cochrane Database Syst Rev 2009;(3):CD001055.

50. Tappin D, Bauld L, Purves D, et al. Financial incentives for smoking cessation in pregnancy: randomised controlled trial. BMJ 2015;350:h134.

51. Gruber J, Koszegi B. Is addiction 'rational'? Theory and evidence. Q J Econ 2001;116:1261-303.

52. Khwaja A, Silverman D. Sloan Frank, Time preference, time discounting, and smoking decisions. J Health Econ 2007;26:927-49.

53. Jusot $F$, Khlat $M$. The role of time and risk preferences in smoking inequalities: a population-based study. Addict Behav 2013;38:2167-73.

54. Brown $\mathrm{H}$, Adams J. The role of time preference in smoking cessation: a longitudinal analysis of data from the Household Income and Labour Dynamics of Australia survey, 2001-08. Addiction 2013;108:186-92.

55. Grignon M. An empirical investigation of heterogeneity in time preferences and smoking behaviors. J Socio Econ 2009;38:739-51.

56. Anderson LR, Mellor JM. Predicting health behaviors with an experimental measure of risk preference. $J$ Health Econ 2008;27:1260-74.

57. Gwaltney CJ, Metrik J, Kahler CW, et al. Self-efficacy and smoking cessation: a meta-analysis. Psychol Addict Behav 2009;23:56-66.
58. Hamilton KR, Mitchell MR, Wing VC, et al. Choice impulsivity: definitions, measurement issues, and clinical implications. Personal Disord 2015;6:182-98.

59. Mitchell SH. Measures of impulsivity in cigarette smokers and nonsmokers. Psychopharmacology 1999;146:455-64.

60. Doran N, Spring B, McChargue D, et al. Impulsivity and smoking relapse. Nicotine Tob Res 2004;6:641-7.

61. McCrae RR, Costa PT. Validation of the five-factor model of personality across instruments and observers. J Pers Soc Psychol 1987:52:81-90.

62. Malouff JM, Thorsteinsson EB, Schutte NS. The five-factor model of personality and smoking: a meta-analysis. J Drug Educ 2006:36:47-58.

63. Terracciano A, Costa PT. Smoking and the five-factor model of personality. Addiction 2004;99:472-81.

64. Inhalateurs électroniques de nicotine. In Rapport de l'OMS (2014). http://apps.who.int/gb/fctc/PDF/cop6/FCTC_COP6_10-fr.pdf

65. ANAES, Agence nationale d'accréditation et d'évaluation en santé Conférence de consensus. Grossesse et tabac. (2004). http://www. has-sante.fr/portail/upload/docs/application/pdf/Grossesse_tabac_ long.pdf (accessed 3 Apr 2016).

66. INPES. Institut national de prévention et d'éducation pour la santé. Grossesse et arrêt du tabac: Accompagner par l'écoute et le dialogue-Les essentiels de l'Inpes_Essentiel_GrossesseArretTabac. pdf. http://www.inpes.sante.fr/30000/pdf/2014/Essentiel_ GrossesseArretTabac.pdf (accessed 3 Apr 2016).

67. MacArthur C, Newton JR, Knox EG. Effect of anti-smoking health education on infant size at birth: a randomized controlled trial. Br J Obstet Gynaecol 1987;94:295-300.

68. Hebel JR, Fox NL, Sexton M. Dose-response of birth weight to various measures of maternal smoking during pregnancy. J Clin Epidemiol 1988;41:483-9.

69. Li CQ, Windsor RA, Perkins L, et al. The impact on infant birth weight and gestational age of cotinine-validated smoking reduction during pregnancy. JAMA 1993;269:1519-24.

70. Benjamin-Garner R, Stotts A. Impact of smoking exposure change on infant birth weight among a cohort of women in a prenatal smoking cessation study. Nicotine Tob Res 2013;15:685-92.

71. Fagerström, K. Determinants of tobacco use and renaming the FTND to the Fagerstrom Test for Cigarette Dependence. Nicotine Tob Res 2012;14:75-8.

72. Berlin I, Singleton E. G, Heishman S. J. Validity of the 12-item French version of the Tobacco Craving Questionnaire in treatmentseeking smokers. Nicotine Tob Res 2010;12:500-7.

73. Hughes JR, Hatsukami D. Signs and symptoms of tobacco withdrawal. Arch Gen Psychiatry 1986;43:289-94.

74. The University of Vermont. Vermont Center on Behavior and Health. https://www.uvm.edu/medicine/behaviorandhealth/?Page=minnws. html\&SM=research_sub.html (accessed 3 Apr 2016).

75. Ewing J. A. Detecting alcoholism. The CAGE questionnaire. JAMA 1984;252:1905-7.

76. Dohmen TJ, Falk A, Heckmann JJ et al. Individual risk attitudes: measurement, determinants, and behavioral consequences. J Eur Econ Assoc 2011;9:522-50.

77. Patton JH, Stanford MS, Barratt ES. Factor structure of the Barratt impulsiveness scale. J Clin Psychol 1995;51:768-74.

78. Baylé FJ, Bourdel MC, Caci $\mathrm{H}$ et al. Structure factorielle de la traduction française de l'échelle d'impulsivité de Barratt (BIS-10)./ Factor structure of the French translation of the Barratt Impulsivity Scale (BIS-10). Can J Psychiatry 2000;45:156-65.

79. Labs SM, Wurtele SK. Fetal Health Locus of Control scale: development and validation. J Consult Clin Psychol 1986;54:814-19.

80. Hukkanen J, Jacob P, Benowitz NL. Metabolism and disposition kinetics of nicotine. Pharmacol Rev 2005;57:79-115.

81. Boffetta P, Hecht S, Gray N, et al. Smokeless tobacco and cancer. Lancet Oncol 2008;9:667-75.

82. Marclay F, Saugy M. Determination of nicotine and nicotine metabolites in urine by hydrophilic interaction chromatographytandem mass spectrometry: potential use of smokeless tobacco products by ice hockey players. $J$ Chromatogr $A$ 2010;1217:7528-38.

83. Marclay F, Grata E, Perrenoud L, et al. A one-year monitoring of nicotine use in sport: frontier between potential performance enhancement and addiction issues. Forensic Sci Int 2011:213:73-84.

84. Nott KH, Vedhara K. The measurement and significance of stressful life events in a cohort of homosexual HIV positive men. AIDS Care 1995;7:55-69.

85. Boyd KA, Briggs AH, Bauld L, et al. Are financial incentives cost effective to support smoking cessation during pregnancy? Addiction 2016;111:360-70. 